\title{
Fluoride intake from regular and low fluoride dentifrices by 2-3-year-old children: influence of the dentifrice flavor
}

\author{
Ingestão de flúor após uso de dentifrícios \\ convencionais e de baixa concentração de flúor \\ por crianças de 2-3 anos de idade: influência \\ do sabor do dentifrício
}

Samanta Mascarenhas Moraes ${ }^{(a)}$ Juliano Pelim Pessan ${ }^{(b)}$ Irene Ramires ${ }^{(c)}$

Marília Afonso Rabelo Buzalaf(d)

(a) Undergraduate Student; (c) MSC; (d) Associate Professor - Department of Biological Sciences, School of Dentistry of Bauru, University of São Paulo.

(b) PhD Student, Department of Pediatric and Social Dentistry, School of Dentistry of Araçatuba, São Paulo State University.

\section{Corresponding author:} Marília Afonso Rabelo Buzalaf Al. Octávio Pinheiro Brisolla, 9-75 (Laboratório de Bioquímica) Bauru - SP - Brazil CEP: 17012-901

E-mail:mbuzalaf@fob.usp.br

Received for publication on Nov 09, 2006 Accepted for publication on Feb 12, 2007

\begin{abstract}
This study evaluated the fluoride intake from dentifrices with different fluoride concentrations ([F]) by children aged 24-36 months, as well as the influence of the dentifrice flavor in the amount of fluoride ingested during toothbrushing. Thirty-three children were randomly divided into 3 groups, according to the $[\mathrm{F}]$ in the dentifrices: $\mathrm{G}-\mathrm{A}$ $(523 \mu \mathrm{gF} / \mathrm{g}), \mathrm{G}-\mathrm{B}(1,062 \mu \mathrm{gF} / \mathrm{g})$ and G-C $(1,373 \mu \mathrm{gF} / \mathrm{g})$. Dentifrices A and B are marketed for children, while dentifrice $\mathrm{C}$ is a regular product. The amount of $\mathrm{F}$ ingested was indirectly obtained, subtracting the amount expelled and the amount left on the toothbrush from the amount initially loaded onto the brush. The results were analyzed by ANOVA, Tukey's test and linear regression analysis $(\mathrm{p}<0.05)$. Children ingested around $60 \%$ of the dentifrice loaded onto the brush, but no significant differences were seen among the groups $(\mathrm{p}>0.05)$. Mean daily fluoride intake from dentifrice for G-A, G-B and G-C was $0.022^{\mathrm{a}}, 0.032^{\mathrm{a}}$ and $0.061^{\mathrm{b}} \mathrm{mg} \mathrm{F} / \mathrm{kg}$ body weight, respectively $(\mathrm{p}<0.01)$. There was a strong positive correlation $(\mathrm{r}=0.86, \mathrm{p}<0.0001)$ between the amount of dentifrice used and the amount of fluoride ingested during toothbrushing. The results indicate the need for instructing children's parents and care givers to use a small amount of dentifrice $(<0.3 \mathrm{~g})$ to avoid excessive ingestion of fluoride. The use of low-[F] dentifrices by children younger than 6 years also seems to be a good alternative to minimize fluoride intake. Dentifrice flavor did not influence the percentage of fluoride intake.
\end{abstract}

Descriptors: Fluorides; Dentifrices; Dental care for children; Dental fluorosis.

Resumo: Avaliou-se a ingestão de flúor após uso de dentifrícios contendo diferentes concentrações de flúor ([F]) por crianças entre 24-36 meses de idade, além da influência do sabor do dentifrício na quantidade de flúor ingerida durante a escovação. Dividiram-se 33 crianças aleatoriamente em 3 grupos, de acordo com a [F] nos dentifrícios: G-A ( $523 \mu \mathrm{gF} /$ g), G-B (1.062 $\mu \mathrm{gF} / \mathrm{g})$ e G-C (1.373 $\mu \mathrm{gF} / \mathrm{g})$. Os dentifrícios A e B são infantis, e o C, convencional. A quantidade de flúor ingerida foi indiretamente obtida subtraindo-se a quantidade de flúor expelida e a quantidade que restou na escova daquela inicialmente carregada na escova. Os resultados foram analisados por ANOVA, teste de Tukey e análise de regressão linear $(\mathrm{p}<0,05)$. Aproximadamente $60 \%$ do dentifrício carregado na escova foi ingerido pelas crianças, embora sem diferenças significativas entre os grupos ( $p>0,05)$. A ingestão média diária de flúor para G-A, G-B e G-C foi 0,022 a $0,032^{\mathrm{a}}$ e $0,061^{\mathrm{b}} \mathrm{mg}$ F/kg de peso corporal, respectivamente $(\mathrm{p}<0,01)$. Houve uma forte correlação positiva $(\mathrm{r}=0,86$, $\mathrm{p}<0,0001$ ) entre a quantidade de dentifrício utilizada e a quantidade de flúor ingerida durante a escovação. Os resultados indicam a necessidade de se instruir pais e cuidadores de crianças a utilizarem uma quantidade pequena de dentifrício $(<0,3 \mathrm{~g})$ para se evitar ingestão excessiva de flúor. O uso de dentifrícios com $[\mathrm{F}]$ reduzida por crianças menores de 6 anos também se constitui numa boa alternativa para se minimizar a ingestão de flúor. O sabor do dentifrício não influenciou na porcentagem de ingestão deste íon.

Descritores: Fluoretos; Dentifrícios; Assistência odontológica para crianças; Fluorose dentária. 


\section{Introduction}

Toothbrushing with fluoridated dentifrices is one of the most widely accepted measures for the control of dental caries, since it combines the mechanical disruption of dental plaque with the therapeutic properties of fluoride $(\mathrm{F})$. Considering that the protective action of fluoridated toothpastes is almost exclusively topical, the ingestion of $\mathrm{F}$ from this source by young children deserves attention, mainly taking into account that the development of the most esthetically important teeth occurs when children are most likely to swallow toothpaste during toothbrushing. ${ }^{6}$

Fluoride intake from dentifrice by 2-3-year-old children has been reported to be around $60 \%$, despite wide variations reported by previous studies. ${ }^{4,7,9,19}$ In Brazil, although the values obtained by Lima, Cury ${ }^{10}$ (2001) and by Paiva et al. ${ }^{14}$ (2003) are close to those reported by other investigators, de Almeida et al. ${ }^{5}$ (2007) showed that the average fluoride intake by children in this age range is close to $80 \%$ and that some children ingested almost $100 \%$ of the paste loaded onto the brush.

Due to concerns about fluoride intake from dentifrice being linked to the increase in the prevalence of dental fluorosis, toothpaste manufacturers have introduced dentifrices with lower $\mathrm{F}$ concentrations for young children. ${ }^{4}$ In the Brazilian market, several brands of dentifrices especially developed for children's use (with special packages and flavors) are available, with fluoride concentrations typically ranging from 500 to $1,100 \mu \mathrm{gF} / \mathrm{g}$. The main concern about these products is the pleasant flavoring agents, which could stimulate children to swallow the dentifrice loaded onto the toothbrush. However, there is no study reporting such relationship.

Thus, the aim of the present study was to evaluate the fluoride intake from dentifrices with different $\mathrm{F}$ concentrations by 2-3-year-old children. By testing conventional dentifrices, as well as products specially marketed for children, the influence of the dentifrice flavor was also evaluated.

\section{Material and Methods Experimental design}

Thirty-three children aged 24-36 months took part in this study. The children lived in Bauru, State of São Paulo, Brazil, a city supplied with fluoridated drinking water (0.6-0.8 mg F/L) ${ }^{16}$ and were attending a public child care center in this city. All the subjects had good oral health and were not using medicines. The protocol for the study was reviewed and approved by the Institutional Review Board (IRB) of the School of Dentistry of Bauru, University of São Paulo. The nature and purposes of the study were explained verbally and in writing to the children's parents who signed an IRB-approved informed consent document.

Children were randomly divided into 3 groups, according to the dentifrices used, as follows:

- Group A ( $\mathrm{n}=12,5$ males, 7 females): Colgate Baby $^{\top \mathrm{M}}$ (Colgate-Palmolive, Osasco, SP, Brazil), having $523 \mu \mathrm{gF} / \mathrm{g}$ as $\mathrm{NaF}$;

- Group B ( $\mathrm{n}=11,6$ males, 5 females): Tandy ${ }^{\mathrm{TM}}$ (Colgate-Palmolive, São Bernardo do Campo, SP, Brazil), having 1,062 $\mu \mathrm{gF} / \mathrm{g}$ as $\mathrm{NaF}$;

- Group C ( $\mathrm{n}=10,5$ males, 5 females): Maxi Fresh $^{\text {TM }}$ (Colgate-Palmolive, São Bernardo do Campo, SP, Brazil), having 1,373 $\mu \mathrm{gF} / \mathrm{g}$ as $\mathrm{NaF}$.

The dentifrices used in groups $\mathrm{A}$ and $\mathrm{B}$ were classified as children's based on packaging, wording and flavoring. Dentifrice C was a regular product (intended for adult use). They were transferred from the original tubes to coded vials, in order to follow a double-blind protocol.

\section{Estimation of fluoride intake from dentifrice}

In order to estimate the fluoride intake from dentifrice, fluoride ingested during toothbrushing was determined as described by Guha-Chowdhury et al. ${ }^{8}$ (1996). Prior to the beginning of the study, all parents and care givers were individually instructed to use the transversal technique to apply the dentifrice on the toothbrush and were asked to repeat this procedure in the presence of the examiner. Using this technique, the amount of paste should have the size of a bean (around 0.25-0.30 g of paste). No restriction was made regarding the length of time spent brushing.

Attempts were made to simulate real conditions by replicating the size of the toothbrush used, the amount of dentifrice spread onto the brush, whether the children expectorated after brushing and 
the length of time spent brushing. Then, two new children's toothbrushes and two tubes of dentifrices were given to each volunteer, for use at home and at the child care center. During one month, children had to brush three times daily using the dentifrices and toothbrushes supplied.

In the experimental day, the toothbrush was weighed $( \pm 0.01 \mathrm{~g})$, the dentifrice was spread onto the toothbrush by the care givers, and the weight of the toothbrush plus dentifrice was recorded. This provided information on the amount of $\mathrm{F}$ loaded onto the brush. Brushing was performed under the observation of the examiner. Depending on the habits, the children were allowed to expectorate or not and to rinse or not. The expectorate was collected in a weighed, plastic, wide-mouth vessel. The toothbrush was thoroughly rinsed with known volumes of deionized water $(50 \mathrm{ml})$, and the rinse was collected in the same vial used to collect the expectorate. This content was analyzed for $\mathrm{F}$, giving the amount of $\mathrm{F}$ expelled and not swallowed. The schematic representation of this procedure is seen in Figure 1. The amount of F ingested was then indirectly derived, by subtracting the amount of $\mathrm{F}$ expelled from the amount initially loaded onto the toothbrush. On this day, the children were also weighed.

\section{Fluoride analysis}

Fluoride concentrations in the dentifrices and in the samples were determined after overnight hexamethyldisiloxane (HMDS)-facilitated diffusion ${ }^{18}$ as modified by Whitford ${ }^{21}$ (1996) using the fluoride ion-specific electrode and a miniature calomel reference electrode (Accumet, \#13-620-79) coupled to a potentiometer (Orion Research, model EA 940). During the diffusion process, which was conducted at room temperature, the solutions in the non-wettable Petri dishes (Falcon, No. 1007) were gently swirled on a rotatory shaker. Fluoride standards $(0.190,0.95,1.90$ and $4.75 \mu \mathrm{gF})$ were prepared by serial dilution of a stock solution of $0.1 \mathrm{M}$ fluoride (Orion 940906) in triplicate and diffused in the same manner as the samples. Comparison with identical non-diffused fluoride standards showed that recovery after diffusion was $>99 \%$. The standard curve had a correlation coefficient $\geq 0.99$. All samples were analyzed in duplicate. The mean repeatability of the fluoride readings, based on the duplicate samples, was $94 \%$.

\section{Statistical analysis}

The data were analyzed by one-way analysis of variance and Tukey's post hoc test for comparison among the groups. Linear regression analysis was also performed to verify the relationship between the amount of fluoride used during toothbrushing and the amount of fluoride ingested. A significance level of $5 \%$ was adopted.

\section{Results}

Table 1 shows the amount of dentifrice used per brushing $(\mathrm{g})$, the amount of fluoride ingested $(\mathrm{mg} /$ $\mathrm{kg}$ ) per brushing episode and per day and the percentage of fluoride ingested per brushing for Groups $\mathrm{A}, \mathrm{B}$ and $\mathrm{C}$. The amount of dentifrice used during toothbrushing spanned a wide range, between 0.11 and $0.71 \mathrm{~g}$ considering all groups; no significant differences were detected among the groups $(p=0.15)$. Similarly, a wide range was also observed with re-

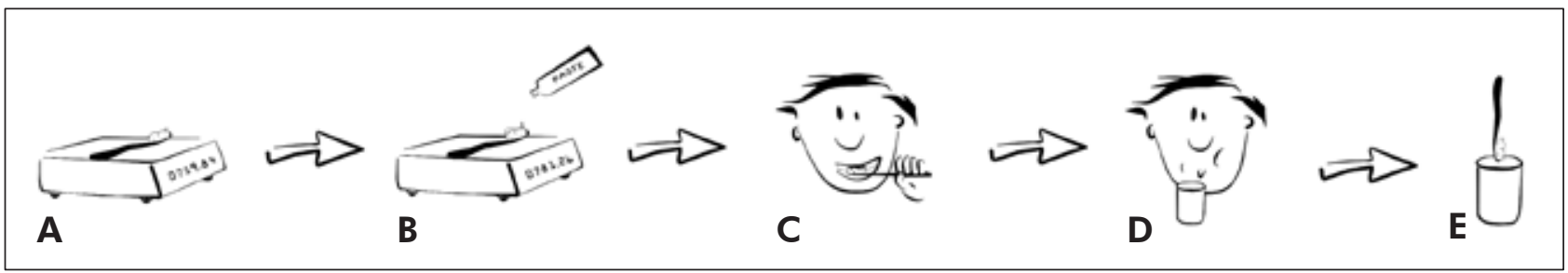

Figure 1 - Schematic representation for estimation of fluoride intake from dentifrice: (A) Toothbrush weighing; (B) toothbrush plus dentifrice weighing; $(\mathbf{C})$ children brushing the teeth as usual; (D) collection of the products of toothbrushing (mixture of dentifrice, saliva and deionized water used to rinse) in a pre-weighed plastic vial; (E) toothbrush washing with deionized water. Based on the study by Guha-Chowdhury et al. ${ }^{8}$ (1996). 
Table 1 - Amount of dentifrice used per brushing, amount of fluoride ingested per brushing episode and per day and percentage of fluoride ingested per brushing for Groups A, B and C.

\begin{tabular}{|c|c|c|c|c|c|c|c|c|c|c|c|c|}
\hline \multirow{2}{*}{ 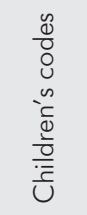 } & \multicolumn{4}{|c|}{ Group A } & \multicolumn{4}{|c|}{ Group B } & \multicolumn{4}{|c|}{ Group C } \\
\hline & 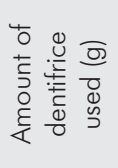 & 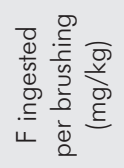 & 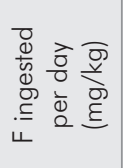 & 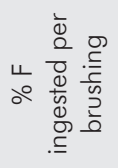 & 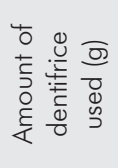 & 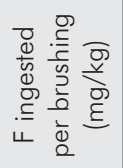 & 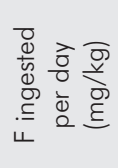 & 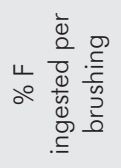 & 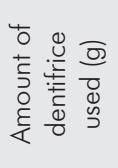 & 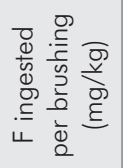 & 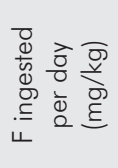 & 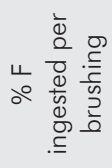 \\
\hline 1 & 0.20 & 0.003 & 0.008 & 34.1 & 0.32 & 0.009 & 0.028 & 42.3 & 0.27 & 0.022 & 0.066 & 70.6 \\
\hline 2 & 0.39 & 0.011 & 0.033 & 65.8 & 0.27 & 0.016 & 0.048 & 73.1 & 0.28 & 0.021 & 0.063 & 68.2 \\
\hline 3 & 0.34 & 0.009 & 0.026 & 66.6 & 0.26 & 0.010 & 0.029 & 59.3 & 0.16 & 0.005 & 0.014 & 35.5 \\
\hline 4 & 0.32 & 0.009 & 0.026 & 79.1 & 0.22 & 0.012 & 0.037 & 71.7 & 0.22 & 0.022 & 0.067 & 75.3 \\
\hline 5 & 0.46 & 0.008 & 0.025 & 68.4 & 0.22 & 0.007 & 0.020 & 39.6 & 0.35 & 0.022 & 0.067 & 59.4 \\
\hline 6 & 0.18 & 0.004 & 0.012 & 72.6 & 0.15 & 0.007 & 0.021 & 54.4 & 0.29 & 0.021 & 0.064 & 76.1 \\
\hline 7 & 0.23 & 0.002 & 0.005 & 20.0 & 0.11 & 0.004 & 0.013 & 48.3 & 0.65 & 0.030 & 0.089 & 41.0 \\
\hline 8 & 0.23 & 0.006 & 0.018 & 81.5 & 0.22 & 0.010 & 0.031 & 71.6 & 0.36 & 0.015 & 0.046 & 51.1 \\
\hline 9 & 0.16 & 0.005 & 0.014 & 84.5 & 0.36 & 0.023 & 0.069 & 79.5 & 0.71 & 0.028 & 0.085 & 40.7 \\
\hline 10 & 0.22 & 0.004 & 0.012 & 54.6 & 0.20 & 0.004 & 0.012 & 26.1 & 0.23 & 0.015 & 0.044 & 65.9 \\
\hline 11 & 0.68 & 0.025 & 0.074 & 84.3 & 0.23 & 0.015 & 0.046 & 90.0 & - & - & - & - \\
\hline 12 & 0.50 & 0.006 & 0.018 & 38.0 & - & - & - & - & - & - & - & - \\
\hline Mean & 0.33 & $0.007^{A}$ & $0.022^{a}$ & 62.5 & 0.23 & $0.011^{\mathrm{A}}$ & $0.032^{a}$ & 59.6 & 0.35 & $0.020^{B}$ & $0.061^{b}$ & 58.4 \\
\hline SE & 0.05 & 0.001 & 0.005 & 6.2 & 0.02 & 0.002 & 0.005 & 5.9 & 0.06 & 0.002 & 0.007 & 4.8 \\
\hline Range & $\begin{array}{l}0.16- \\
0.68\end{array}$ & $\begin{array}{l}0.002- \\
0.025\end{array}$ & $\begin{array}{l}0.005- \\
0.074\end{array}$ & $\begin{array}{l}20.0- \\
84.5\end{array}$ & $\begin{array}{l}0.11- \\
0.36\end{array}$ & $\begin{array}{l}0.004- \\
0.023\end{array}$ & $\begin{array}{l}0.013- \\
0.069\end{array}$ & $\begin{array}{l}26.1- \\
90.0\end{array}$ & $\begin{array}{l}0.16- \\
0.71\end{array}$ & $\begin{array}{l}0.005- \\
0.030\end{array}$ & $\begin{array}{l}0.014- \\
0.089\end{array}$ & $\begin{array}{l}35.5- \\
76.1\end{array}$ \\
\hline
\end{tabular}

Different superscript letters in the same row indicate significant differences among groups regarding the amount of fluoride ingested per brushing episode (upper case letters) and per day (lower case letters) $(\mathrm{p}<0.05)$. Children from groups A, B and C used Colgate Baby ${ }^{\mathrm{TM}}(523 \mu \mathrm{gF} / \mathrm{g})$, Colgate Tandy ${ }^{\mathrm{TM}}$ $(1,062 \mu \mathrm{gF} / \mathrm{g})$, and Colgate Maxi Fresh ${ }^{\mathrm{TM}}(1,373 \mu \mathrm{gF} / \mathrm{g})$, respectively.

spect to the percentage of fluoride ingestion per brushing episode (between 20 and $90 \%$ ) and no significant differences were detected among the groups ( $\mathrm{p}=0.87$ ).

Regarding $\mathrm{F}$ ingested per brushing episode and per day, significant differences were observed between Groups A and C $(\mathrm{p}<0.001)$ and between Groups B and C $(\mathrm{p}<0.01)$. One child from Group A and two children from group $\mathrm{C}$ exceeded the maximum total desirable fluoride intake per day $(0.07 \mathrm{mg}$ $\mathrm{F} / \mathrm{kg}$ body weight) considering $\mathrm{F}$ ingested from this source only. ${ }^{3}$ However, most of the children did not exceed this limit.

Fluoride ingestion from dentifrice was shown to be strongly and positively correlated with the amount of dentifrice used during toothbrushing considering all groups together $(r=0.86$, $\mathrm{p}<0.0001$ ), as seen in Graph 1. For groups A, B

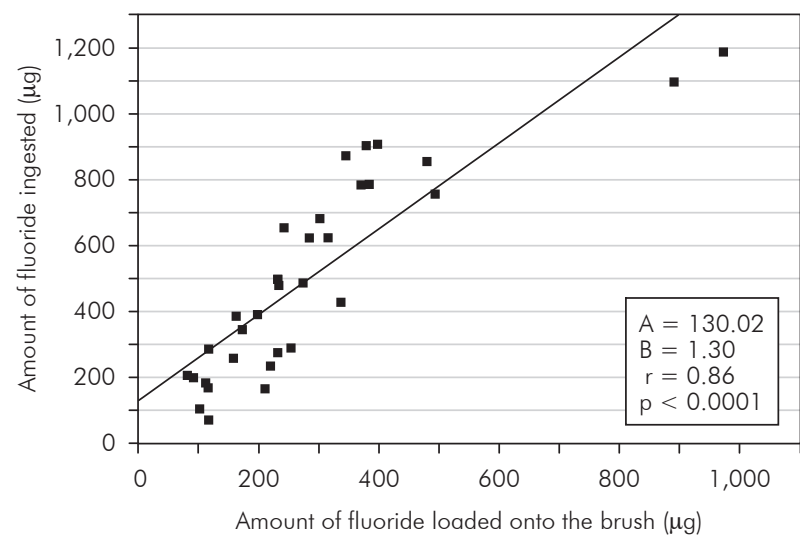

Graph 1 - Correlation between the amount of fluoride loaded onto the brush and the amount ingested.

and $\mathrm{C}$ separately, the coefficients of determination $(\mathrm{r})$ were $0.87(\mathrm{p}<0.001), 0.78(\mathrm{p}<0.01)$ and 0.85 $(\mathrm{p}<0.01)$, respectively. 


\section{Discussion}

The increase in the prevalence of dental fluorosis observed in the last decades has prompted studies aiming to investigate the reasons for such an increase, as well as the possible risk factors. Among these, the relationship between the use of fluoridated toothpastes by young children and the development of dental fluorosis has been demonstrated by many investigators. ${ }^{11,12,15}$

Table 1 shows that the ingestion of fluoride from toothpaste was around $60 \%$ of the amount initially put onto the toothbrush. Similar findings were also reported by studies conducted with children in the same age range and with a similar protocol, ${ }^{10,14}$ while other investigators have found even higher values. ${ }^{4,5,7}$ It seems that the dentifrice flavor had no influence on fluoride intake, since the percentage of fluoride intake one month after using the dentifrices was quite similar for all the groups. This is important information, since the literature suggests that the flavor of the dentifrice may interfere in fluoride intake during toothbrushing, but there is no scientific evidence for this assumption.

Furthermore, it was observed that 23 children $(70 \%)$ ingested more than $50 \%$ of the dentifrice during toothbrushing and some of them ingested almost all the dentifrice loaded onto the brush, in agreement with the findings reported by de Almeida et al. ${ }^{5}$ (2007). Moreover, 3 children exceeded the maximum total desirable fluoride intake per day $(0.07 \mathrm{mg} / \mathrm{kg})$, considering only $\mathrm{F}$ ingested from this source. This happened with children that brushed their teeth using amounts of paste above $0.65 \mathrm{~g}$, regardless of the dentifrice used (child 11 from G-A and children 7 and 9 from G-C). Even though this happened with less than $10 \%$ of the children studied, this finding is of concern especially when the $\mathrm{F}$ intake from other sources is considered. If the contribution of the dentifrice to the total $\mathrm{F}$ intake by children at this age range is assumed to be around $60 \%, 7,10,14$ almost $40 \%$ of the children would exceed the total daily $\mathrm{F}$ intake (child 11 from G-A, children 2, 9 and 11 from G-B and children 1, 2, 4-10 from G-C). Therefore, besides supervising children during toothbrushing, parents and care givers must also stimulate them to spit out the toothpaste, since most of the children in this age range are not able to do so by themselves.

One point that deserves attention is that the amount of paste loaded on the toothbrush by the care givers varied widely (with values up to $0.71 \mathrm{~g}$ ), although they were instructed individually to put 0.25-0.30 g. A similar large variation was also found by Franco et al..$^{7}$ (2005) in a study conducted in four Colombian cities with different socioeconomic status. This assumes a greater importance when considering the strong and positive relationship between the amount of dentifrice used and the amount ingested during toothbrushing (Graph 1). These data analyzed together indicate that the first measure for reducing $\mathrm{F}$ intake from dentifrice by young children is to reduce the amount of dentifrice used. Instructions on that must be given and reinforced to parents and care givers by dental professionals, and those instructed must be evaluated periodically, since it was noticed that some care givers did not follow the instructions given in the beginning of the study. In an attempt to address this matter, the use of liquid dentifrices has been suggested in order to make easier the standardization of the amount of dentifrice used during toothbrushing. Vilhena et al. ${ }^{20}$ (2006) have shown that the amount of dentifrice put onto the toothbrush by 178 children was more than twice as lower when a liquid dentifrice was used, in comparison to a toothpaste.

Concerning the total amount of fluoride ingested from the dentifrices, the values obtained for G-A, G$\mathrm{B}$ and $\mathrm{G}-\mathrm{C}$ were directly related to the fluoride concentrations of the dentifrices used in these groups. The absence of significant differences between G-A and G-B, however, was not expected, since the percentage of dentifrice ingestion was similar for all groups. The lower amount of paste (mean \pm se) used during toothbrushing by G-B $(0.23 \pm 0.02 \mathrm{~g})$ compared to G-A $(0.33 \pm 0.05 \mathrm{~g})$ may have influenced these results. It is probable that significant differences among all groups could be found in a study conducted with a higher number of subjects. Anyway, the results obtained in the present study indicate that the use of dentifrices with lower F concentrations by young children can be an effective measure 
for minimizing the amount of $\mathrm{F}$ ingested from this source.

In this sense, the European Academy of Paediatric Dentistry recommends the use of a very small amount of low-F-concentration dentifrice from 6 months to 2 years of age and the use of a peasized amount of $500 \mathrm{ppm} F$ twice daily from 2 to 6 years. ${ }^{13}$ The main concern of this recommendation is the possibility of increasing the risk of dental caries, considering that an inverse relationship between $\mathrm{F}$ concentration in the dentifrice and the prevalence of dental caries has been demonstrated. ${ }^{17}$ However, in vitro studies showed that toothpastes in acidic $\mathrm{pH}$ containing $550 \mu \mathrm{gF} / \mathrm{g}$ ( $\mathrm{pH} 5.5$ ) or $412 \mu \mathrm{gF} / \mathrm{g}$ $(\mathrm{pH} 4.5)$ have an effectiveness similar to that of a neutral dentifrice with $1,100 \mu \mathrm{gF} / \mathrm{g} .{ }^{1,2}$ The clinical efficacy of such formulations remains to be tested, but these results indicate the possibility of using these formulations in the future.

It is noteworthy that most of the Brazilian dentifrices manufactured for children's use have F concentrations similar to that found in conventional products. To date, there are few low-F dentifrices available and these are much more expensive than the regular ones, which makes their use by low socio-economic level children very difficult. In addi-

\section{References}

1. Alves KM, Pessan JP, Brighenti FL, Franco KS, Oliveira FA, Buzalaf MA et al. In vitro evaluation of the effectiveness of acidic fluoride dentifrices. Caries Res. 2007;41(4):263-7.

2. Brighenti FL, Delbem ACB, Buzalaf MAR, Oliveira FAL, Ribeiro DB, Sassaki KT. In vitro evaluation of acidified toothpastes with low fluoride content. Caries Res. 2006;40(3):239-44.

3. Burt BA. The changing patterns of systemic fluoride intake. J Dent Res. 1992;71(5):1228-37.

4. Cochran JA, Ketley CE, Sanches L, Mamai-Homata E, Oila AM, Árnadottír IB et al. A standardized photographic method for evaluating enamel opacities including fluorosis. Community Dent Oral Epidemiol. 2004;32(Suppl 1):19-27.

5. de Almeida BS, da Silva Cardoso VE, Buzalaf MA. Fluoride ingestion from toothpaste and diet in 1- to 3-year-old Brazilian children. Community Dent Oral Epidemiol. 2007;35(1):5363.

6. Evans RW, Stamm JW. An epidemiologic estimate of the critical period during which human maxillary central inci- tion, it is important to highlight that the labeling as well as the marketing of the low-fluoride dentifrices in Brazil is not adequate. In their labels it is not emphasized that they are indicated for small children in order to reduce the risk of dental fluorosis. Furthermore, their labeling is similar to that of conventional dentifrices and this may make parents confused when choosing the adequate products for their children. In this sense, a specific legislation for the labeling and marketing of such products is necessary.

\section{Conclusions}

In summary, the results of the present study reinforce the need for instructing parents and care givers to use small amounts of paste during toothbrushing and to stimulate children to spit out the dentifrice in order to reduce the ingestion of $\mathrm{F}$ from this source. In addition, the use of dentifrices with lower F concentrations should be indicated for young children. Fluoride ingestion from dentifrice does not seem to be influenced by its flavor.

\section{Acknowledgements}

This study was supported by the State of São Paulo Research Foundation (FAPESP) (Proc. 2005/04017-9).

sors are most susceptible to fluorosis. J Public Health Dent. 1991;51(4):251-9.

7. Franco AM, Martignon S, Saldarriaga A, González MC, Arbeláez MI, Ocampo A et al. Total fluoride intake in children aged 22-35 months in four Colombian cities. Community Dent Oral Epidemiol. 2005;33(1):1-8.

8. Guha-Chowdhury N, Drummond BK, Smillie AC. Total fluoride intake in children aged 3 to 4 years - a longitudinal study. J Dent Res. 1996;75(7):1451-7.

9. Levy SM, Warren JJ, Davis CS, Kirchner HL, Kanellis MJ, Wefel JS. Patterns of fluoride intake from birth to 36 months. J Public Health Dent. 2001;61(2):70-7.

10. Lima YBO, Cury JA. [Fluoride intake by children from water and dentifrice] [Article in Portuguese]. Rev Saúde Pública. 2001;35(6):576-81.

11. Mascarenhas AK, Burt BA. Fluorosis risk from early exposure to fluoride toothpaste. Community Dent Oral Epidemiol. 1998;26(4):241-8. 
12. Milsom K, Mitropoulos CM. Enamel defects in 8-year-old children in fluoridated and non-fluoridated parts of Cheshire. Caries Res. 1990;24(4):286-9.

13. Oulis C, Raadal M, Martens L. Guidelines on the use of fluoride in children: An EAPD policy document. Eur J Paediatr Dent. 2000;1(1):7-12.

14. Paiva SM, Lima YBO, Cury JA. Fluoride intake by Brazilian children from two communities with fluoridated water. Community Dent Oral Epidemiol. 2003;31(3):184-91.

15. Pereira AC, da Cunha FL, Meneghim MC, Werner CW. Dental caries and fluorosis prevalence study in a nonfluoridated Brazilian community: trend analysis and toothpaste association. J Dent Child. 2000;67(2):132-5.

16. Ramires I, Maia LP, Rigolizzo DS, Lauris JRP, Buzalaf MAR. Heterocontrole da fluoretação da água de abastecimento público em Bauru, SP, Brasil. Rev Saúde Pública. 2006; (in press).

17. Stephen KW, Creanor SL, Russell JI, Burchell CK, Huntington E, Downie CF. A 3-year oral health dose-response study of sodium monofluorophosphate dentifrices with and without zinc citrate: anti-caries results. Community Dent Oral Epidemiol. 1988;16(6):321-5.

18. Taves DR. Separation of fluoride by rapid diffusion using hexamethyldisiloxane. Talanta. 1968;15:969-74.

19. van Loveren C, Ketley CE, Cochran JA, Duckworth RM, O'Mullane DM. Fluoride ingestion from toothpaste: fluoride recovered from the toothbrush, the expectorate and the after-brush rinses. Community Dent Oral Epidemiol. 2004;32 Suppl 1:54-61.

20. Vilhena FV, Silva HM, Sales-Peres SHC, Caldana ML, Buzalaf MAR. Drop technique: the control of the amount of fluoride dentifrice used by young children [abstract]. Caries Res. 2006;40(4):304.

21. Whitford GM. The metabolism and toxicity of fluoride (Monographs in Oral Science). $2^{\text {nd }}$ ed. Basel: Karger; 1996. 